\section{Two Cheers for Nuclear Physics}

CRITICISM of the way in which the UK has supported big science was given by Sir Harry Melville, the retired chairman of the Council for Scientific Policy, in the Appleton Memorial Lecture to the Institution of Electrical Engineers. In nuclear physics, Sir Harry said, the home effort was certainly too large if the powerful international facilities to which the UK contributes were taken into account. "By arranging better collaboration in Europe, considerable economy could have been achieved in the construction and operation of machines of moderate size." It was argued, Sir Harry said, that nuclear physicists needed to be trained on medium-sized machines if they were to use the bigger international machines. "Yet many countries in Europe do not have national machines and they still work effectively with the international facility." If national prestige were to be an index of success, the accelerators in the UK had been badly timed.

Big projects well timed, on the other hand, could give the country a lead for many years over other countries and add to its scientific prestige. Radiotelescopes, Sir Harry thought, had been well timed and, although the capital cost of the equipment was high, the costs of running telescopes were relatively low. Radio astronomers were also more useful in industry than others, because of their varied experience. But Sir Harry had nothing kind to say about big optical telescopes in Britain. "In optical astronomy the utilization of telescopes is very low indeed because of the atmospheric conditions and it is questionable whether any large telescope should ever have been installed in this country. The natural trend is to erect telescopes in countries overseas where observing conditions can be relied on for long periods of the year."

The next few years would be of great importance to the universities. The Government had announced the financial provision for the next five years, and the research councils knew how much they would be getting in the next three years. Sir Harry was unimpressed. "The increase in moneys year by year is extremely modest, having regard to the job which has to be done, especially in science. A good deal of re-thinking and pruning will have to be done if quality is to be maintained . . . there can be a very real danger of stagnation if vigilance is not maintained and management is not made effective."

\section{ELDO Hopeful}

WITHIN the next fortnight, all being well, the next launching in the ELDO programme will take place from Woomera, Australia. ELDO staff are hoping that the launching, called F6/2, will make up for the disappointment of the last launching, which went perfectly until after the separation of the first and second stages. The second stage engines failed to ignite. ELDO is confident, however, that the failure did not reflect on the design of the second stage, but was caused by an electronic failure. For the next firing, simple modifications have been introduced to prevent the same thing happening again.

For the F6/2 launching, the second stage will again be live, and the upper stages will carry the basic elements of systems intended for full test in later flights.
It will be the first flight for testing all the separation systems for all three stages and for satellite injection. After separation, the second and third stage plus satellite will continue in ballistic flight a small distance from each other. The impact zone, in the Pacific some 2,300 miles from Woomera, will be reached in about 18 minutes.

\section{Robbing Peter, Paying Paul \\ from our Oxford Correspondent}

OXFORD colleges vary greatly in wealth, from the older men's colleges-St John's, Christ Church and All Souls - with their munificent endowments, to the penury of the newer men's colleges and most of the women's. Shortage of money has put the members of poorer colleges at a disadvantage in many ways; it is difficult for them to appoint tutors in recondite subjects, so that many students have to be taught outside their colleges. Stipends at some women's colleges have been very considerably lower than those at men's colleges, and there have been far fewer tutors for the same number of undergraduates.

Congregation has now, however, passed a statute which, it is hoped, will eliminate these disparities. Colleges are to contribute to a university fund on a sliding scale so that the poorer colleges will be paying nothing and the richer ones up to a quarter of their income above $£ 150,000$. The fund will then be distributed among the poorer colleges so that eventually the endowments of all colleges will exceed $£ 600,000$, $£ 200,000$ more than the figure recommended by the Franks Commission. The contribution of colleges to the fund will be assessed according to capital rather than income. The Franks Commission had originally recommended an assessment on the basis of capital as being ideal, for certain colleges have large amounts of capital yielding low interest rates, but the commission concluded that this method of assessment would be too difficult to undertake, and decided that contributions should be evaluated on the basis of college incomes. The problem of valuation now lies with the University Chest and the College Contributions Com. mittee, which will be administering the scheme from July 31 next year.

Transitional arrangements have been made: the two graduate colleges, St Anthony's and Nuffield, which specialize in the social sciences, will be taxed by the university at a lower rate than undergraduate colleges. For some time, grants to poorer colleges have been made by the Common University Fund, but the last payments of this kind have been made in the form of $£ 80,000$ to be divided between three colleges, and all the work of making the colleges financially equal will now be carried out by the Contributions Committee.

\section{Hydrofoils or Hovercraft?}

THE British interest in hovercraft has tended to overshadow hydrofoils, another interesting development. Mr R. Gresham Cook, Conservative MP for Twickenham, is alarmed about this, and opened an adjournment debate on the subject in the House of Commons last week. While Britain has been building 40 hovercraft, he said, nearly 1,000 hydrofoils-craft the bows of which are raised from the water by the action of wing. 
like foils-were in operation all over the world. Even in rough water, the ride in a hydrofoil is comparatively smooth-better, it seems, than in a craft of the same weight without hydrofoils. Mr Cook said that hydrofoils are cheaper to manufacture than hovercraft, although more expensive than conventional passenger ships.

In April this year, the Ministry of Technology established a working party to examine the design, construction and operation of hydrofoils. Its chairman is $\mathrm{Mr} \mathrm{A}$. Silverleaf, deputy director of the National Physical Laboratory, and among its members are Mr Peter Dory, who operates a hydrofoil service between Jersey and Guernsey and the French coast, and Mr M. N. Parker, of the British Ship Research Association. So far the committee has been involved with a survey of the possible markets for hydrofoils; when this is finished it will turn to the research side.

Research on hydrofoils has in fact been undertaken at the Ship Division of the National Physical Laboratory. This has been work of a fairly fundamental nature, including studies of the lift produced by the hydrofoils and the forces experienced by them. There has also been some work on propeller design and on the behaviour of the hydrofoils in waves. Experience at the NPL confirms that hydrofoils ought to be able to manage in conditions at sea. Costs depend greatly on the degree of sophistication. At the NPL, work has been carried out on surface piercing foils, which are likely to need less sophisticated control than other types. With surface piercing foils, changes of speed are automatically taken care of by the shape of the foils. If, for example, the craft slows down and sinks into the water, a greater area of foil becomes an effective lift surface, and the necessary lift is maintained. If speed is increased the effective area of foil is reduced, and the craft retains roughly the same attitude. Fully submerged foils, on the other hand, call for more complicated control systems, more like those of aircraft.

Many of those involved deny that there is any conflict between hovercraft and hydrofoils, and say that there is room for both. In a recent paper presented to a Canadian symposium (and reprinted in Flight International on October 19) Mr Christopher Cockerell, inventor of the hovercraft, suggested that hydrofoils would be more suitable at speeds below 40 knots and sizes of less than 100 tons. Mr Cockerell's paper suggests that hovercraft and hydrofoils would be similar in cost, but hovercraft pay a heavy penalty by the lack of suitable engines. With better engines, fuel costs, which amount to 25 per cent of total operating costs, could be reduced by a factor of two or three.

\section{Regulated Surpluses}

Nationaltzed industries in Britain may from time to time complain that they are starved of capital, but there is no doubt that they are generously supplied with decrees by the Government about the conduct of their affairs. The most recent of these is the White Paper on the economic and financial objectives laid down for the various industries (HMSO, 1s. 9d.). For practical purposes, this document is a revised version of that which appeared in 1961 and which first laid it down that nationalized industries should earn a surplus on the capital employed in their busi- nesses which would be comparable in many ways with the profits earned by commercial industries. The issue is important because of its influence on the prices charged by the several industries and because of the way in which it affects decisions about large items of capital expenditure.

The new document is more a statement of general principles than a set of detailed instructions-the ministers responsible for individual industries will issue them. The Treasury, which determines general policy, suggests that a revision or at least a restatement of policy has been made necessary by the "important technological changes and discoveries of natural resources" since 1961, but it is also clear that the anomalous differences which have sprung up between different industries have contributed to the need for rationalization. No doubt the Government has in mind the way in which the electricity industry, now wishing to invest in nuclear power stations, should aim at a higher rate of return than the gas industry, now unexpectedly prosperous.

Differences like these should be comfortably ironed out by the doctrine, now promulgated, that decisions about alternative forms of capital investment should be based on the same kind of calculation-one which has the effect of making the effective rate of interest a cool 8 per cent. This is the rate the Central Electricity Generating Board will have to use in calculating the economic balance between nuclear reactors and conventional power stations. This, too, is how the Gas Council will have to make decisions about alternative ways of using gas from the North Sea. This is a good start, and it is also sensible that the new statement of policy should emphasize the importance of linking the prices charged for the products and services of the nationalized industries with the marginal costs of providing them. If this means that the new commercial Post Office will charge less for trunk telephone calls, everybody will be delighted. But it is also important that the new policy statement emphasizes that industries need not slavishly aim to earn the surpluses laid down for them, for this may help in future to avoid some of the absurdities about electricity prices which there have been this summer. In other words, the new White Paper is full of good sense, although it does not go so far as to suggest that ministers should in future refrain from nullifying the benefits of sound policy by pointless interference.

\section{More Money for France}

A substantial increase of the spending of the French Government on scientific research and development is allowed for in the budget for 1968, now adopted. There will be an increase of 17 per cent in the total cost of supporting what is described as scientific and technical research through the public purse, so that the amount spent in the year ahead will be approximately 1,591 million francs. The programme for assisting the development of computers, and the programme of space research, will each receive an extra 20 per cent. One of the greatest of the various increases in the year ahead is that for the support of space research, which will be absorbing an extra 68 million francs. Support for science and technology through the educational budget is substantial, and will take an extra 96 million francs in 1968. 